\title{
Infant posterior neocortical lesions do not induce visual responses in spared anterior neocortex
}

\author{
THACKERY GRAY \\ The Ohio State University, Columbus, Ohio 43210 \\ and \\ T. E. LeVERE \\ North Carolina State University, Raleigh, North Carolina 27650
}

\begin{abstract}
Infant posterior neocortex lesions enhance the significance of anterior neocortex for acquisition of a two-choice brightness discrimination. The present research was designed to determine if this result was an effect of neocortical reorganization inducing anterior neocortex to assume the functions of visual neocortex. However, attempts to record visual evoked responses from anterior neocortex were unsuccessful. It was concluded that whatever infant posterior neocortical lesions do, they do not cause the surviving anterior neocortex to vicariously function for the lost visual neocortex. An explanation is offered in terms of more general facilitatory influences of neocortex.
\end{abstract}

A recent and important experiment in the continuing investigation of the effects of early brain damage has been reported by Howarth, Meyer, and Meyer (1979). The significant feature of this research was that the consequences of neonatal brain injury were assessed as a function of how this injury interacted with additional brain injury sustained later in life. Specifically, Howarth et al. reported that a brightness discrimination was learned with equal efficiency by both the infant visual decorticate rat and the adult visual decorticate rat. However, while subsequent anterior decortication has little consequence for the adult lesioned rat, this same operation completely disrupts the previously learned brightness discrimination in the infant lesioned animal.

While there are a number of possible explanations of this result, the electrophysiological consequences of early sensory manipulation (Blakemore \& Cooper, 1970; Dews \& Wiesel, 1970; Freeman \& Thibos, 1973; Hirsh \& Spinelli, 1971; Hubel \& Wiesel, 1965, 1970; Pettigrew \& Freeman, 1973; Wiesel \& Hubel, 1963)

This research was supported by Research Grant MH 011 from the National Institute of Mental Health to Donald R. Meyer and Patricia M. Meyer and by Research Grant NS 12459 from the National Institute of Neurological and Communicative Disorders and Stroke, U.S. Department of Health, Education and Welfare to T. E. LeVere. T. Gray's current address: Department of Psychology, Spence Laboratories of Psychology, The University of Iowa, Iowa City, Iowa 52242. Address reprint requests to: T. E. LeVere, Neuropsychology Laboratory, Department of Psychology, North Carolina State University, Raleigh, North Carolina 27650. The authors wish to thank P. Knowles for her assistance in the preparation of this report. suggest that induced reorganization of anterior neocortex might be the most viable proposition. The argument would be that in early infancy there is a "critical period" when the neopallium is plastic and will demonstrate morphological and/or functional changes in response to any number of experimental manipulations. In the present case, the experimental manipulation is the destruction of the primary visual neocortex, and the effect is to induce the noninjured anterior neocortex to vicariously function for the ablated visual area. Similar lesions in adulthood would not produce any such reorganization because the neocortex loses this neonatal plasticity during maturation. Thus, the disruption of a brightness discrimination by anterior neocortical lesions in neonatal visual decorticates reflects the fact that, during development, the anterior cortex assumes the functions normally mediated by the lesioned visual neocortex. The purpose of the present experiment was to evaluate this proposition. To do this, we assessed the visual evoked electrophysiological activity of the anterior neocortex in animals deprived of their visual cortices in infancy.

\section{METHOD}

\footnotetext{
Subjects

The subjects for this experiment were seven adult male hooded rats. Two of the rats were normal, one was prepared with a posterior visual neocortical ablation at $\mathbf{9 0}$ days of age, and the remaining four were prepared with similar lesions at 7 days of age. All animals were housed individually under standard laboratory conditions and allowed free access to food and water.
} 


\section{Apparatus}

The average evoked response to visual stimulation was recorded in an electrically shielded room. The animals were held in a Kopf stereotaxic instrument and placed on a heating pad to assist in maintaining normal body temperature. Evoked responses were induced by a Grass photostimulator positioned some $50 \mathrm{~cm}$ from the animal's eye. The number " 4 " intensity setting of the photostimulator was used for all recording sessions.

Electroencephalographic (EEG) and heart-rate (HR) analogue signals were passed unamplified from the shielded room to Grass 7P5Il amplifiers. From these amplifiers, the analogue signals were successively fed to a Rockland bandpass filter and then to the A/D converters of a PDP-12A computer. The Grass amplifier was set to bandpass between $1 \mathrm{~Hz}$ and $1 \mathrm{kHz}(60 \mathrm{~Hz}$ filter off), while the Rockland filter was set to bandpass between $1 \mathrm{~Hz}$ and $.1 \mathrm{kHz}$. The A/D conversion rate was $2 \mathrm{k}$ points per second to eliminate frequency aliasing. Visual evoked responses were computed on the accumulation of 25 light flashes with 500 A/D conversion points $(250 \mathrm{msec})$ of EEG activity stored after each flash.

\section{Procedure}

The infant surgeries were accomplished at the Comparative and Physiological Laboratories at the Ohio State University in accordance with the procedures described by Howarth et al. (1979). The adult visual decortications were performed at the North Carolina State University laboratories, using the methods described by LeVere and Morlock (1973), 2 weeks prior to recording.

Prior to EEG recording, each animal was administered $.2 \mathrm{ml}$ atropine, ip, and then anesthetized with Urethane $(1.5 \mathrm{mg} / \mathrm{kg})$, ip. The rat was then installed in the stereotaxic instrument, and a small ring was used to retract the eyelid of the eye contralateral to the hemisphere from where the average evoked responses were to be recorded. The pupil was dilated, and the eye was kept moist with applications of atropine. The ipsilateral eye was covered with black electrician's tape. Two stainless steel suture clips were attached bilaterally to the skin over the subject's rib cage for heart-rate recording. A third stainless steel suture clip was attached midway on the subject's back for grounding purposes. Body temperature was monitored with a rectal thermometer.

To accomplish average evoked response recording, a sagittal incision was made over the hemisphere and the skin was retracted. The bone was then drilled to accommodate the recording electrodes. Care was taken when drilling the bone not to damage the overlying dura and to inflict the smallest possible insult in order to afford maximum physiological protection to the underlying neocortex. Mineral oil-saturated cotton pellets, warmed to $38^{\circ} \mathrm{C}$, were placed over the incision to further maintain the integrity of the preparation.

Visual evoked responses were monopolarly recorded and referenced to an indifferent electrode buried within the neck muscle. Two electrode arrangements were used. Initially all animals were recorded with a linear electrode array consisting of seven .5-mmtipped gold-plated electrodes spaced approximately $2 \mathrm{~mm}$ center to center. This electrode array was organized in a parasagittal plane some $2 \mathrm{~mm}$ lateral to midline. The anterior-posterior orientation of this array was such that numbering the electrodes from front to back positioned the third and fourth electrodes equally on either side of a line perpendicular to the sagittal suture and passing through bregma (see Figure 3 ).

After a minimum of 2 weeks had elapsed since recording with the linear electrode array, the infant lesioned animals were returned for a second recording session. The only difference between the earlier recording session and this one was that the subjects were prepared with 14 small dental burr holes organized in the matrix shown in Figure 6, and a stainless steel insect pin insulated to within $1 \mathrm{~mm}$ of its tip was used to record the EEG activity. After the subject had been prepared for the particular electrode array to be used, the quality of the EEG and HR signals was checked. Additionally, an "average evoked response" was computed with the subject's eye covered to confirm that the experimental setup was not subject to electrical artifact. After this, the subject was left to stabilize in the darkened recording room for a minimum of $2.5 \mathrm{~h}$. During this stabilization period, the subject's temperature, EEG, and HR were continuously monitored. At no time did the temperature drop below $36^{\circ} \mathrm{C}$ or the EEG show any indication of depression.

After the stabilization period, a minimum of two recording runs with the linear array was accomplished for each subject. A run consisted of computing individual average evoked responses (25 light flashes) at each of the seven electrode positions. The flash rate for each evoked response was $1 / \mathrm{sec}$, and a 5 -min period separated the computation of the average evoked response at each electrode. One of the runs was from the anterior electrode to the posterior electrode, while the other run was from the posterior electrode to the anterior electrode, with the direction of the first and second runs balanced across subjects. When the infant lesioned animals were rerecorded with the matrix electrode array, the individual average evoked responses were recorded from each of the sites, starting with the most posterior site of the most medial parasagittal row and progressing to the most anterior electrode, and then to the most anterior electrode of the adjacent row and progressing backward, and so on. As with the recording using the linear array, each average was computed on the basis of 25 flashes, with the flash rate set at 1 flash/sec. Five minutes separated the computation of each average evoked response.

In addition to these formal recording sessions, a number of other averages were computed. These averages were primarily for verification of our recording parameters and involved responses computed on more than 100 light flashes at interflash intervals ranging from $50 \mathrm{msec}$ to $5 \mathrm{sec}$.

The infant lesioned animals were brought to histology, and given a lethal dose of sodium pentobarbital, and perfused intracardially with saline followed by $10 \%$ buffered Formalin. The brains were removed, and the extent of the visual lesion was drawn on surface diagrams. After this, the brains were frozen, sectioned, and stained with cresyl violet for microscopic analysis.

\section{RESULTS}

\section{Histology}

Figure 1 presents the surface diagrams of the four infant lesioned animals. In all cases, the posterior neocortex was destroyed throughout its dorsolateral extent. Microscopic analysis showed that the LGNd was often collapsed, with only optic fibers of passage occupying its space. Because the brainstem was often indented at the level of the LGNd, the lateral posterior nucleus was shifted more laterally and the LGNv had come to rest slightly above its normal position. These observations were similar to those of Cunningham, Huddleston, and Murray (1979) and indicated complete destruction of the visual neocortex.

\section{Electrophysiology}

Figure 2 presents the computed average evoked response as displayed by our PDP-12A computer. This particular response was from an electrode positioned directly over the visual neocortex in an adult normal rat. In contrast with this sort of response, with over 90 measurements from $1 \mathrm{~mm}$ posterior to bregma to the anterior pole in normal rats, in rats sustaining visual decortication in adulthood, and in rats sus- 
taining visual decortication at 7 days of age, there was never the slightest indication of an EEG response related to the photic stimulation.

Figure 3 illustrates the results from a normal adult rat. As can be seen from the figure, the flash produced a rather well-defined visual evoked response at posterior locations up to and including the electrode positioned approximately $3 \mathrm{~mm}$ posterior to bregma. As has been summarized by LeVere (1978), this corresponds quite closely to both the anatomical and electrophysiological definition of the primary visual neocortex (Area 17).

Figure 4 summarizes similar recordings from an adult rat which had sustained posterior neodecortication some 2 weeks prior to the recording session. The rather low and questionable levels of coherent EEG activity over the lesioned area most probably reflect volume conduction from subcortical centers. However, there is absolutely no indication of a visual evoked response in any of the electrodes anterior to these posterior three electrodes.

Figure 5 presents recordings from a rat deprived of its visual neocortex at 7 days of age. The evokedpotential picture is the same. Also, and notably, the activity averaged from the most posterior four electrodes is extremely depressed in comparison with that of the rat deprived of its visual neocortex in
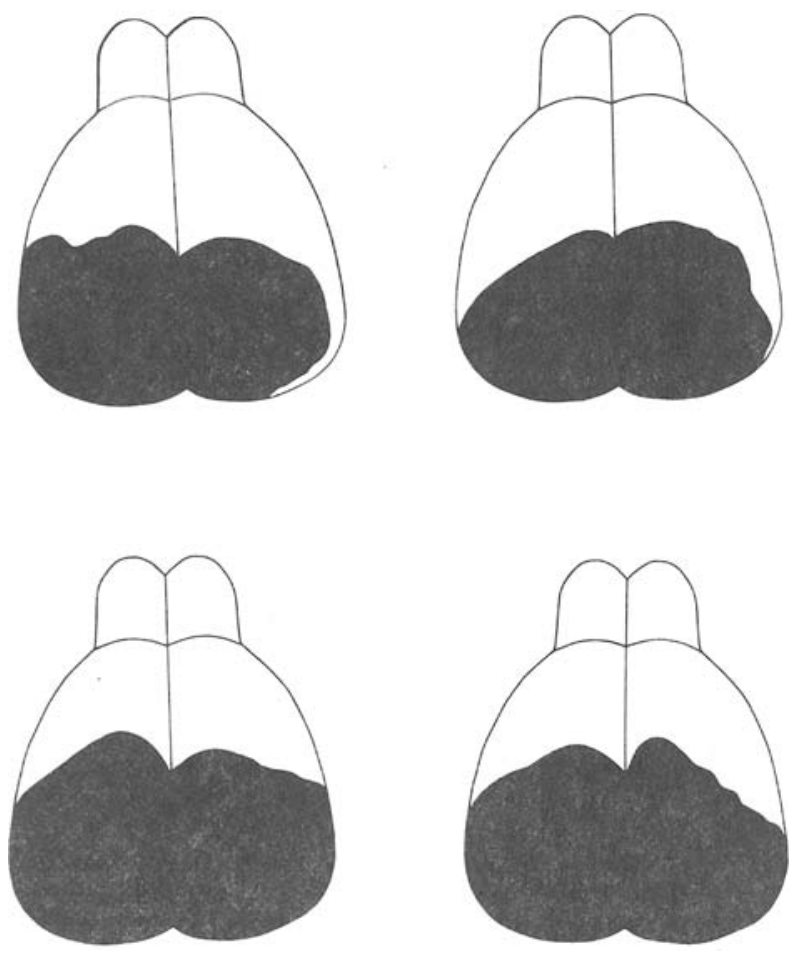

Figure 1. Diagram of surface lesions of four rats prepared with posterior neocortical lesions at 7 days of age.

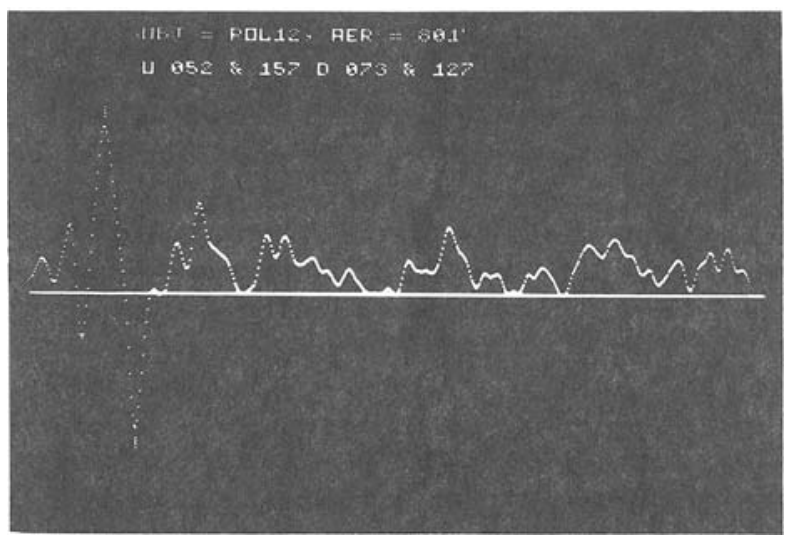

Figure 2. Photograph of average evoked response from normal adult rat. This average, and all others, was computed on the basis of 25 light flashes at the rate of 1 flash/sec. Each flash was timelocked to 250 msec of surface-recorded EEG record, successively bandpass filtered between $1 \mathrm{~Hz}$ and $1 \mathrm{kHz}$ and $1 \mathrm{~Hz}$ and $.1 \mathrm{kHz}$ before $A / D$ conversion at rate of $2 k$ points per second.

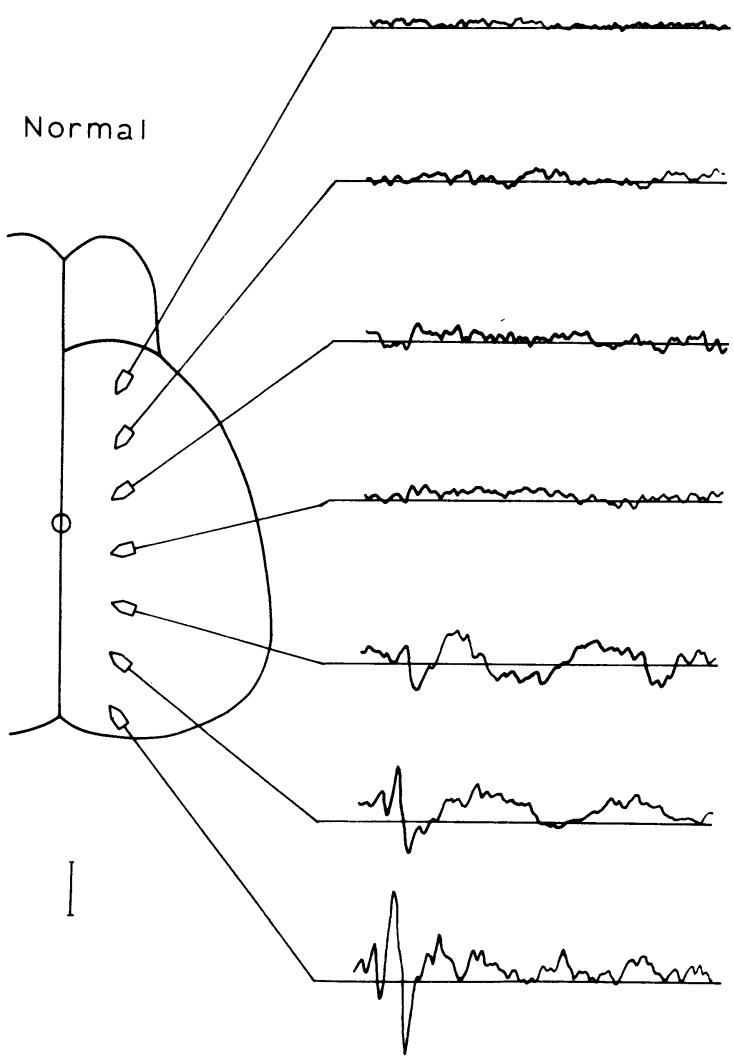

Figure 3. Average evoked response from an adult normal rat. The linear electrode array was positioned some $2 \mathrm{~mm}$ from midline, and the interelectrode distance was $2 \mathrm{~mm}$. The small circle represents bregma. The vertical line in the lower left is the average of a $50-\mu \mathrm{V}$ calibration signal. All responses were traced from photographs similar to that shown in Figure 2. 


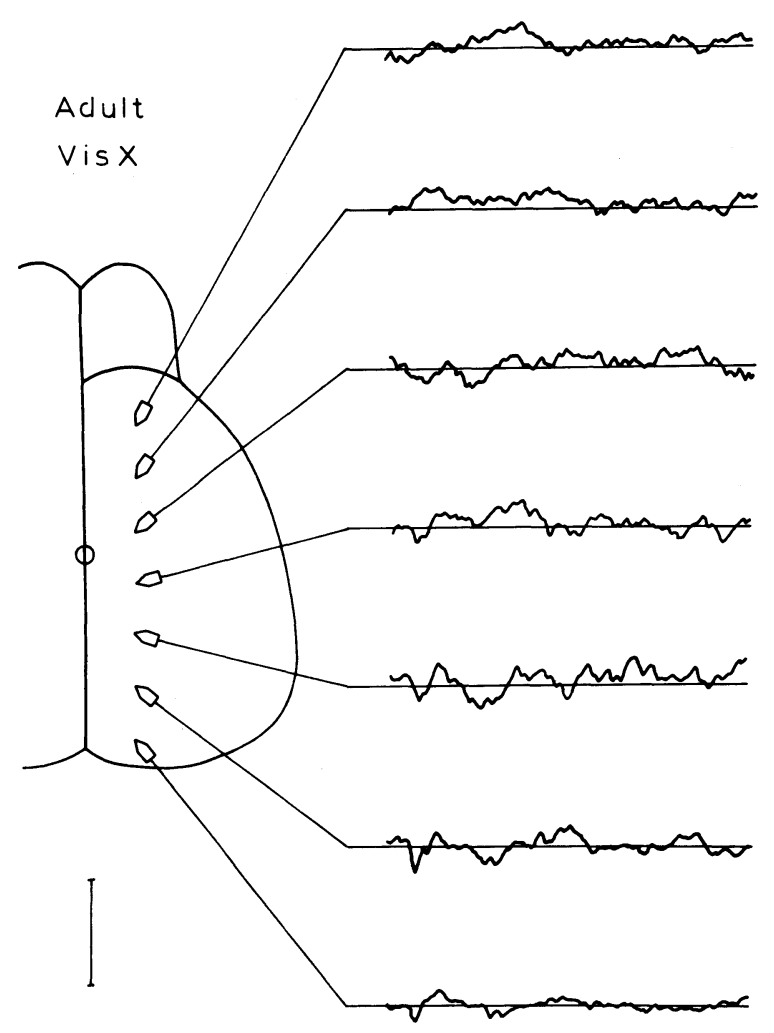

Figure 4. Average evoked response from an adult rat subjected to posterior neodecortication at 90 days of age. See Figure 3 for details.

adulthood. On the other hand, the anteriormost three electrodes appear more typical of both the normal animal and the animal lesioned in adulthood, yet there is still absolutely no indication that the electrical activity is driven by the photic stimulation.

Figure 6 is typical of the activity we recorded from infant lesioned animals prepared for the matrix recording procedure. Again, as with all of our other recordings, there is absolutely no indication of a visual evoked response over the dorsal surface of the anterior neocortex.

It should finally be mentioned that the same results were found in the averages computed at the anterior cortex that involved over 100 light flashes at interflash intervals ranging from $50 \mathrm{msec}$ to $5 \mathrm{sec}$. In none of these were we able to detect any EEG activity related to the visual stimulation.

\section{DISCUSSION}

From the time Kennard $(1936,1938,1942)$ investigated the effects of neonatal motor cortex injury, it has been explicitly assumed that the behavioral effects of early brain injury were less severe than similar injuries sustained in adulthood. While the unitary simplicity of this assumed facilitation has recently been questioned (Goldman, 1974; Isaacson, 1975; Johnson \& Almli, 1978; Schneider, 1979), it nonetheless would seem clear that there are differential behavioral effects of early neonatal brain injury and brain injury sustained at maturity. For example, early visual lesions will change the significance of the anterior neocortex with respect to visually guided behavior, while the same lesion in adulthood will not (Howarth et al., 1979). The problem addressed by the present research concerned the fundamental nature of these induced changes in the anterior neocortex following infant visual decortication.

Specifically, we questioned whether posterior decortication in the infant developing brain might promote sufficient neural reorganization to allow the surviving anterior neocortex to vicariously function for the visual neocortex. Clearly, an infant visual neocortical ablation enhances the importance of the anterior neocortex in the acquisition and/or retention of a two-choice brightness discrimination. This, in turn, indicates that there is considerable latitude available to the developing mammalian brain with regard to what areas will ultimately participate in the occurrence of specific behaviors. However, this latitude does not appear to extend to functional reorganiza-

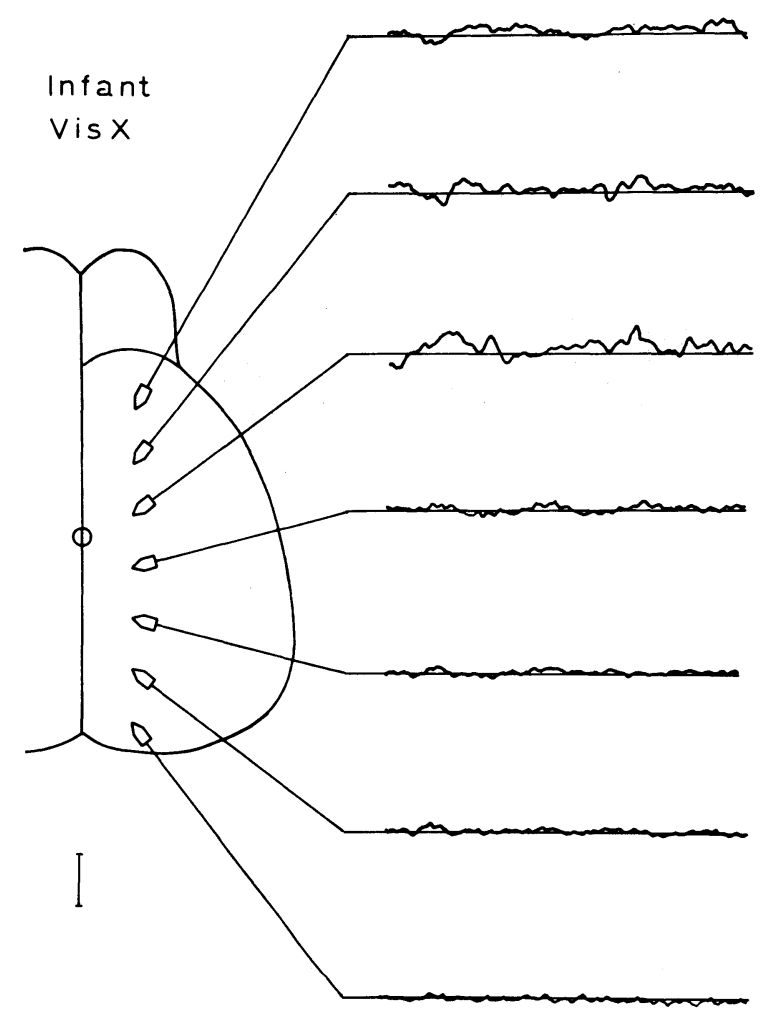

Figure 5. Average evoked response from an adult rat subjected to posterior neocortication at 7 days of age. See Figure 3 for details. 


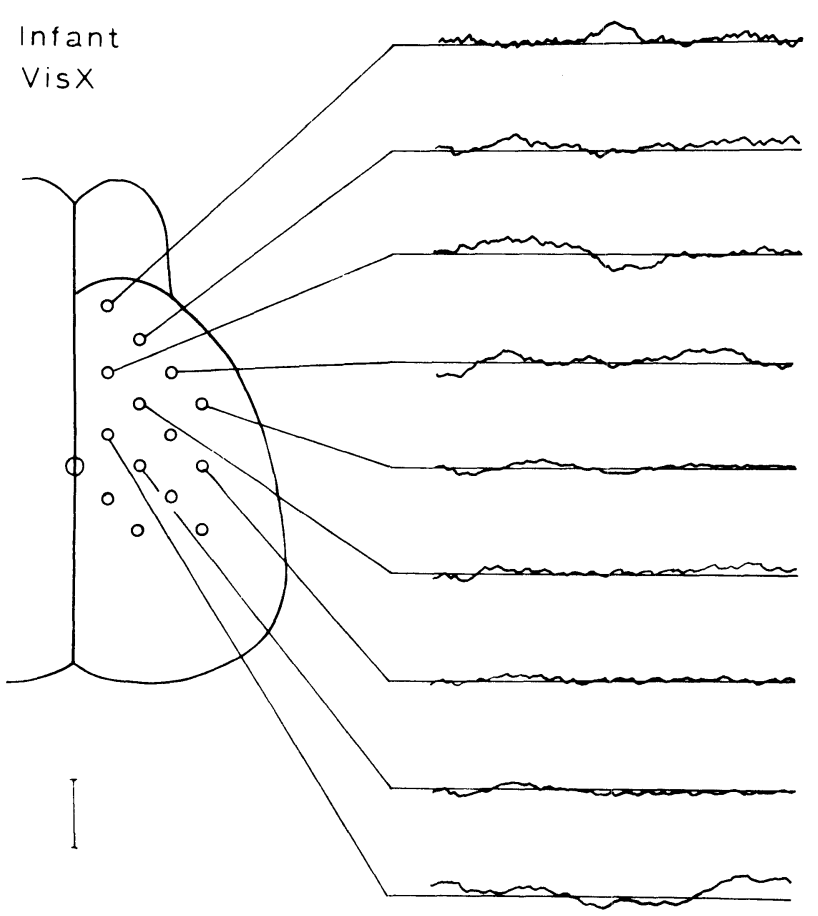

Figure 6. Representative average evoked responses from the matrix electrode array used with the infant lesioned rats. The rows and columns of electrodes are each spaced $2 \mathrm{~mm}$ apart. See Figure 3 for other details.

tion. In fact, our inability to detect evoked visual activity from the anterior neocortex in any of our preparations suggests rejection of, or at least exercising extreme caution in advocating, the occurrence of sufficient developmental reorganization to allow vicarious functioning following infant visual lesions.

Unfortunately we cannot at present offer more positive evidence concerning the functional nature of the anterior neocortex following infant visual neocortical ablations. However, the demonstrated importance of corticofugal facilitatory input to related subcortical centers (Sprague, 1966) and certain tenets of developmental neurobiology offer a suggestion which may have some ultimate merit. In this regard, it is now fairly well agreed that there is an initial quantitative imbalance between source and target neurons in the developing brain (Jacobson, 1978; Lund, 1978). This initial imbalance is subsequently corrected by either phylogenetic, morphogenetic, or histogenetic cell death of the source neurons (Glucksman, 1951, 1965). Although the exact mechanisms that determine which cells will survive and which cells will not survive is less than completely understood, the establishment of an effective synapse and what Jacobson (1978) has called "functional validation" appears to play a central role. Now, if the entire normal infant neocortex projects rather diffusely to subcortical centers, with the ultimate projections determined by some trophic affinity at the synapse, then the presence of the visual neocortex may override the significance of other neocortical areas with respect to influencing diencephalic visual centers. However, if the developing rat is deprived of its visual neocortex, then the other neocortical projections may become correspondingly more important and provide the necessary corticofugal influence to these subcortical visual centers. In this manner, it might be possible for a nonvisual neocortical area to affect visual behavior without completely subsuming all of the specific functions of the posterior visual neocortex.

Obviously this proposition is humbly offered as only a speculation. Yet it is in keeping with the findings of Howarth et al. (1979) and the present failure to detect vicarious visual functioning of the anterior neocortex in rats deprived of their primary visual neocortices in infancy. And, more importantly, the proposition is amenable to anatomical investigation.

\section{REFERENCES}

Blakemore, C., \& Cooper, G. F. Development of the brain depends upon the visual environment. Nature, 1970, 228, 477-478.

Cunningham, T. J., Huddelston, C., \& Murray, M. Modification of neuron numbers in the visual system of the rat. Journal of Comparative Neurology, 1979, 184, 423-434.

Dews, P. B., \& Wiesel, T. N. Consequences of monocular deprivation on visual behavior in kittens. Journal of Physiology, 1970, 206, 437-455.

Freeman, R. D., \& Thibos, L. N. Electrophysiological evidence that abnormal early visual experience can modify the human brain. Science, 1973, 180, 876-878.

Glucksman, A. Cell deaths in normal vertebrate ontogeny. Biological Review, 1951, 26, 59-86.

Glucksman, A. Cell death in normal development. Archives of Biology, 1965, 76, 419-437.

Goldman, P. S. An alternative to developmental plasticity: Heterology of CNS structures in infants and adults. In D. G. Stein, J. J. Rosen, \& N. Butters (Eds.), Plasticity and recovery of function in the central nervous system. New York: Academic Press, 1974

Hirsch, H. V. B., \& Spinelli, D. N. Modification of the distribution of receptive field orientation in cats by selective visual exposure during development. Experimental Brain Research, 1971, 13, 509-527.

Howarth, H., Meyer, D. R., \& Meyer, P. M. Perinatal injuries to the visual cortex enhance the significance of extravisual cortex for performance of a visual habit. Physiological Psychology, 1979, 7, 163-166.

HubeL, D. H., \& Wiesel, T. N. Binocular interaction in striate cortex of kittens reared with artificial squint. Journal of Neurophysiology, 1965, 28, 1041-1059.

Hubel, D. H., \& Wiesel, T. N. The period of susceptibility to the physiological effects of unilateral eye closure in kittens. Journal of Physiology, 1970, 206, 419-436.

IsAACSON, R. L. The myth of recovery from early brain damage. In N. R. Ellis (Ed.), Aberrant development in infancy. Hillsdale, N. J: Erlbaum, 1975.

J Acobson, M. Developmental neurobiology (2nd ed.). New York: Plenum Press, 1978. 
Johnson, D., \& Almli, C. R. Age, brain damage, and performance. In S. Finger (Ed.), Recovery from brain damage. New York: Plenum Press, 1978.

KenNARD, M. A. Age and other factors in motor recovery from precentral lesions in monkeys. American Journal of Physiology, 1936, 115, 138-146.

KENNARD, M. A. Reorganization of motor function in the cerebral cortex of monkeys deprived of motor and premotor areas in infancy. Journal of Neurophysiology, 1938, 1, 477-497.

KEnNARD, M. A. Cortical reorganization of motor function. Studies on series of monkeys of various ages from infancy to maturity. Archives of Neurology and Psychiatry, 1942, 48, 227-240.

LEVERE, T. E. The primary visual system of the rat: A primer of its anatomy. Physiological Psychology, 1978, 6, 142-169.

LeVere, T. E., \& Morlock, G. W. The nature of visual recovery following posterior decortication in the hooded rat. Journal of Comparative and Physiological Psychology, 1973, 83, 62-67.
Lund, R. D. Development and plasticity of the brain. New York: Oxford University Press, 1978.

Pettigrew, J. D., \& Freeman, R. D. Visual experience without lines: Effect on developing cortical neurons. Science, 1973, 182, 599-601.

Schneider, G. E. Is it really better to have your brain lesion early? A revision of the "Kennard principle." Neuropsychologia, 1979, 17, 557-583.

SPRAGUe, J. M. Interaction of cortex and superior colliculus in mediation of visually guided behavior in the cat. Science, 1966, 153, 1544-1547.

Wiesel, T. E., \& Hubel, D. H. Single-cell responses in striate cortex of kittens deprived of vision in one eye. Journal of Neurophysiology, 1963, 26, 1003-1017.

(Received for publication February 11, 1980; revision accepted July 29, 1980.) 